\title{
APRESENTAÇĀO DE DOCUMENTOS REFERENTES AO PENSAR, AGIR E FAZER DE WANDA AGUIAR HORTA
}

Kazuko Uchikawa Graziano * Junia Villela Goncalves**

GONÇALVES, J.V. \& GRAZIANO, K.U. Apresentação de documentos referentes ao pensar, agir e fazer de Wanda de Aguiar Horta. Rev. Esc. Enf. USP, São Paulo, 21(n\%/especial): 13-20. 1987.

Iniciando esta nossa apresentação, gostariamos de fazer um breve relato da origem deste nosso trabalho, bem como, das dificuldades e descobertas que nos acompanharam.

Durante o nosso curso de Mestrado, na disciplina de Tendências de Enfermagem, que cursamos no $2^{\circ}$ semestre de 85 , fizemos parte do grupo que estudou e apresentou, em sala de aula, a Teoria das Necessidades Humanas Básicas de Wanda de Aguiar Horta.

$\mathrm{Na}$ ocasião, foi nos dada a oportunidade de consultar um rico acervo deixado pela $\mathrm{Dr}^{\mathrm{a}}$ Wanda. O material que consistia em transparências para retroprojeção, fichas de aula, reproduções de textos, programas de cursos, bibliografias, cartazes e anotações informais, além de vasto, estava bastante desordenado.

Devido à exiguidade do tempo, pouco pudemos aproveitar, na ocasião, para a apresentação do nosso trabalho, porém, pudemos perceber o valor nêle contido.

Passada a apresentação, nós nos propusemos a organizar o material, pois percebemos que este trabalho nos levaria a uma reflexão mais profunda sobre a Enfermagem, através das idéias da Dr. Wanda. Por outro lado, a organização facilitaria consultas posteriores a todos que se dedicassem a continuar os estudos com base na sua obra.

Inicialmente, julgamos que o trabalho fosse simples, bastando restaurar o material e ordenar o mesmo, classificando-o em torno dos temas centrais.

\section{ENGANO!}

Para uma boa parte do material, o trabalho foi um dificil jogo de quebra-cabeças.

A reconstrução da estrutura de pensamento da Dra Wanda, através do material didático por ela deixado, não foi fácil, e nem podemos afirmar com segurança, que conseguimos ordená-los de forma coerente.

\footnotetext{
* Enfermeira. Auxiliar de Ensino do Departamento de Enfermagem Médico-Cirúrgica da Escola de Enfermagem da USP - Disciplina Enfermagem em Centro-Cirúrgico.

*: Enfermeira Encarregada de Setor do Hospital Infantil Menino Jesus da Prefeitura Munlcipal de São Paulo. Aluna do Curso de Pós-Graduação - Nivel de Mestrado da EEUSP.
} 
Nas primeiras vezes que nos reunimos para o trabalho, percebemos quanto o espirito da Dra Wanda era inquieto. Sempre insatisfeita com o ponto que havia chegado, ampliava os temas em extensão e profundidade, parecendo buscar a Essência e a Verdade.

Transparências com o mesmo título e introdução, tinha várias. Cada assunto retomado, era acrescido de novas informações e conceitos que o ampliavam.

Trechos manuscritos, provavelmente produtos do "insight" em papel de rascunho qualquer, também encontramos muitos, mostrando um espírito que pensava constantemente perseguindo a Verdade.

Preocupava-se com recursos didáticos.

A retroprojeção foi uma técnica inovadora da época e que a Dra Wanda lançou mão na maior parte de suas aulas. Cores vivas e variadas foram utilizadas. Cartazes com pontos principais de um tema eram confeccionados. Era informal. Complementava as transparências no decorrer de suas aulas, enxertando comentários que julgasse pertinentes.

O seu material mostra-nos, claramente, que a prática não reflexiva da Enfermagem, inquietava a $\mathrm{Dr}^{\circ}$ Wanda. Precocemente percebeu que era necessário um sistema teórico que unificasse o saber científico de Enfermagem. Essa preocupação é bastante evidente pela persistência com que abordou o assunto.

Essa mesma inquietação foi, provavelmente, o que levou a procurar conhecer como a Enfermagem era praticada nos centros mais avançados. A grande quantidade de literatura sobre as bases teóricas e filosóficas da Enfermagem que leu, traduziu, publicou e organizou em referências, além da sua própria produção científica, serviu, sem dúvida, para antecipar a divulgação, o interesse e discussão sobre o assunto, nas Escolas de Enfermagem Brasileiras.

A TEORIA DAS NECESSIDADES HUMANAS BÁSICAS, e a sua operacionalização, o Processo de Enfermagem, foi o auge de tudo que fez pela Enfermagem - UM MARCO INDELÉVEL NA ENFERMAGEM BRASILEIRA. . .

Este nosso trabalho que consistiu na restauração e organização do material didático que pertenceu à $D^{a}$. Wanda e que ora fará parte do acervo bibliográfico desta Escola, ficará à disposição, para consulta, na Biblioteca da E E US P.

Consta de 7 pastas, com material classificado nos seguintes temas centrais:

- Teoria das Necessidades Humanas Básicas.

- Processo de Enfermagem.

- Filosofia de Enfermagem e Existencialismo. 
- Teoria de Enfermagem.

- Pensar e Maturidade.

- Tendências de Enfermagem.

- Assuntos Variados:

- Procedimentos

- Cuidados

- Inferência Clínica

Paralelamente a este trabalho, surgiu um outro, que foi a compilação de todas as publicações da $\mathrm{Dr}^{*}$ Wanda em periódicos nacionais.

Para nos ajudar na organização do material didático, recorremos várias vezes, como guia, a essas publicações, pois $\mathrm{Dr}^{\text {a }}$ Wanda não costumava colocar datas no seu material didático, ou às vezes nem a paginação mostrando a seqüência das transparências.

Trabalhamos na organização, muitas vezes, baseando-nos no tipo da letra, cor da caneta hidrográfica que usava e, logicamente, a "pista" maior foi a seqüência aparentemente lógica do desenvolvimento de um assunto. Satisfação e orgulho era o que sentíamos quando concluíamos a montagem de uma pasta.

Após consulta destas publicaçōes, achamos de grande valia ordená-las em seqüência cronológica e encaderná-las para colocar também à disposição para consulta àqueles que se dedicassem a continuar os estudos com base na obra da Dra Wanda.

Surgiram, então, os dois volumes encadernados que ora colocamos também à disposição para consulta.

Um dos volumes consiste em editoriais, artigos, traduçōes e poesias que publicou na Revista Enfermagem em Novas Dimensōes, que criou e editou durante 5 anos sem o apoio de qualquer órgão oficial e o outro volume, artigos que escreveu na Revista Brasileira de Enfermagem, Revista da Escola de Enfermagem da U. S. P. e comunicações científicas na Revista Ciência e Cultura da S. B.P.C. e um artigo que escreveu no Diário Oficial do Estado.

A análise destas publicaçōes será feita agora, pela colega Júnia, que dará continuidade à nossa apresentação.

Nesta segunda parte de nossa apresentação temos o objetivo de tentar transmitir a evolução do pensamento de Wanda Horta acompanhando trechos de sua vasta publicação em periodicos.

Iremos ver como desde o inicio de sua carreira profissional Dr Wanda manifestava insatisfação com a forma como a enfermagem vinha sendo praticada e suas propostas para melhorar esta situação, que culminaram com a Teoria das Necessidades Humanas Básicas e o Processo de Enfermagem. 
Serão projetadas transparências dos trechos comentados para facilitar o seguimento das idéias.

O trecho que apresentaremos a seguir faz parte do artigo Conceito de Enfermagem (1), escrito por Horta em 1951, quando trabalhava no Paraná, três anos após ter se graduado pela Escola de Enfermagem da Universidade de São Paulo. Ela dizia então:

"O que se faz nos hospitais brasileiros não é enfermagem, e sim uma pseudo-enfermagem. $O$ objetivo de todas as atenções, a finalidade do serviço, tem por centro o médico. Fazer tudo do melhor modo possível para evitar o aborrecimento do médico. Há uma inversão de valores."

Sua produção mais ativa em periódicos se inicia por volta de 1964, quando já era professora da Escola de Enfermagem da USP onde tra. balharia até 1981, ano de seu falecimento.

A seguir citaremos um trecho do artigo Aspectos do Conforto do $\mathrm{Pa}$ ciente em Hospitais ${ }^{(2)}$, onde Dra Wanda continua manifestando seu descontentamento com a prática vigente:

"O que temos podido observar nos hospitais em matéria de conforto ao paciente, não só nos serviços puramente assistenciais e gratuitos, mas até mesmo nos particulares e pagos é tão desanimador que quase nos leva a concluir: NOS HOSPITAIS OFERECEMOS O MÁXIMO DE DESCONFORTO AOS INTERNADOS."

Foi sem dúvida essa insatisfação o fator desencadeante de suas pesquisas que visavam descobrir uma forma mais racional e eficiente de se praticar a enfermagem.

No artigo Considerações sobre o Diagnóstico de Enfermagem, em 1967, Dra Wanda começa a introduzir a idéia de que a enfermagem deveria ser praticada de forma mais científica:

"O enfermeiro, por diversos fatores, está habilitado a fazer o diagnóstico de enfermagem. Este diagnóstico baseia-se na observação, percepção e levantamento dos problemas e necessidades do indivíduo, familia e comunidade. Com os dados obtidos, o enfermeiro formulará hipóteses plausiveis que, sujeitas à experimentação ou raciocínio lógico, serão ou não aceitas como hipóteses verdadeiras. Firmado o diagnóstico, será traçado o plano assistencial que se baseia na compreensão dos principios sobre os quais se firmam as medidas tomadas para solver os problemas dos individuos, grupos ou comunidades; finalmente, na determinação das reações dos mesmos à solução dos problemas. Dentro deste novo esquema de trabalho a enfermagem se encaminhará para a pesquisa em amplos setores que até o momento se conservam inexplorados e mesmo, desconhecidos." (3) 
Notamos que ela já começa a utilizar o termo necessidade como foco de atenção da enfermagem. Ainda não fala em necessidade humana básica, mas a idéia já começa a tomar forma.

Outro ponto que nos chama atenção em seus artigos é a bibliografia citada, sempre atualizada. Estudava as modernas teorias, à medida que as mesmas eram publicadas, tendo sido uma verdadeira pioneira do estudo de teorias de enfermagem no Brasil.

Retornando à evolução de seu pensamento, encontramos em um artigo de $1967^{(4)}$ sua primeira definição de necessidades básicas:

"Necessidades são certas condições que precisam ser atendidas a fim de que $o$ indivíduo conserve a vida e mantenha seu bem estar. As necessidades básicas são aquelas relacionadas à conservação da vida e à segurança. Na enfermagem consideramos as seguintes: respiração, circulação, alimentação, sono e repouso, exercício, termoregulação, higiene, conforto físico, vestuário, ambiente adequado, comunicação, amor, necessidade gregária e religiosa, realização, aprovação e recreação."

No mesmo artigo, a definição de plano de cuidados:

"Plano de cuidados é o roteiro da execução dos cuidados de enfermagem adequados às necessidades básicas, especificas de cada paciente, que coordena a ação da equipe de enfermagem."

No artigo anterior Wanda Horta já havia citado o diagnóstico de enfermagem e o plano assistencial (3). Neste (4), ela fala sobre o plano de cuidados. Embora não os cite como etapas de Processo de Enfermagem, aparentemente o mesmo estava já tomando forma.

De quanto pudemos concluir do estudo de sua obra, tanto a Teoria das Necessidades Humanas Básicas como o Processo de Enfermagem foram sendo criados concomitantemente, se alternando em seus artigos textos mais técnicos e outros onde predomina a definição de conceitos.

E em $1968{ }^{(5)}$ que ela publica pela primeira vez seu próprio conceito de enfermagem:

"Enfermagem é a ciência e a arte de assistir o ser humano no atendimento de suas necessidades básicas, de torná-lo independente desta assistência através da educação; de recuperar, manter e promover sua saúde, contando para isso com a colaboração de outros grupos profissionais."

Seguindo nesta linha, em 1970 ela apresenta no XXII Congresso Brasileiro de Enfermagem em São Paulo, o trabalho Contribuição para uma Teoria de Enfermagem (6).

Nele, a autora reconhece que a enfermagem é ainda empirica e sugere a urgência do desenvolvimento de teorias que expliquem a enfermagem em si e contribuam para lhe dar sistematização e organização. 
Correlaciona uma série de fatos referentes ao homem e à enfermagem, e vemos então a Teoria das Necessidades Humanas Básicas já concebida em sua essência:

“...a) a enfermagem como parte integrante da equipe de saúde procurará manter, promover e recuperar a saúde do homem, portanto mantê-lo em estado de equilibrio; implementa movimentos positivos, previne movimentos negativos e reverte movimentos negativos em positivos. b) a enfermagem como parte integrante da equipe de saúde implementa movimentos positivos, previne movimentos negativos e reverte movimentos negativos em positivos, pela assistência ao homem no atendimento de suas necessidades básicas, visando o seu equilíbrio dentro de um universo dinâmico no tempo e no espaço. Nessa última conclusão, ampla, considerada como a essência do que seria uma teoria de enfermagem, estabelece-se uma série conseqüente de conceitos, princípios e proposições; definição de enfermagem, necessidades básicas, diagnóstico de enfermagem, assistência de enfermagem; enumeração de princípios relacionados à enfermagem e proposição sobre o corpo de conhecimentos da enfermagem a ser sistematizado e organizado, e que diz respeito ao estudo das necessidades humanas básicas, os fatores que sobre elas atuam alterando suas manifestaçōes e atendimento e os meios para atendê-las."

No ano seguinte em Manaus, Wanda Horta apresenta a metodologia do Processo de Enfermagem, completando assim a parte fundamental de sua obra, ou seja, a Teoria das Necessidades Numanas Básicas e sua operacionalização.

A configuração esquemática do Processo de Enfermagem ainda viria a sofrer alterações, diminuindo de 8 para 6 fases, e se tornando um sistema fechado, e não aberto como ela o apresentou na ocasião ${ }^{(7)}$ :

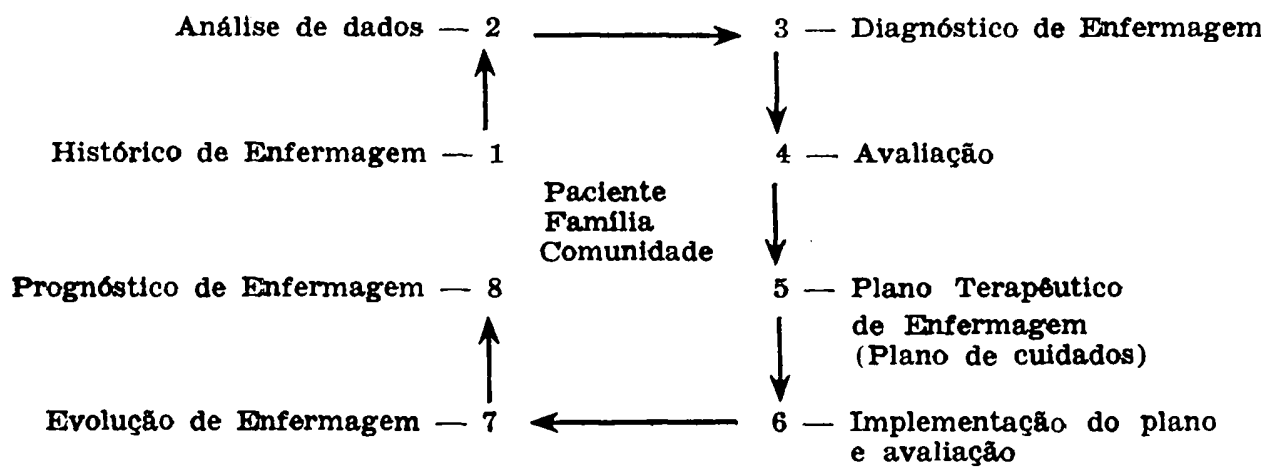

Além disso, neste artigo ela ainda define a terminologia utilizada, 
Metodologia: "A arte de guiar o espírito na investigaçåo da verdade". "Estudo científico dos métodos". "A ciência dos métodos, regras, procedimentos, etc., como é aplicado por uma ciência ou arte".

Processo: "Série de açōes sistemáticas visando certo resultado, ato de proceder; ação de ser feito progressivamente". Qualquer fenômeno que mostra uma contínua mudança no tempo, como o processo de crescimento; uma série de ações ou operações que conduzem definitivamente a um fim".

Processo de enfermagem: $\dot{E}$ a dinâmica das açōes sistematizadas de enfermagem visando a assistência de enfermagem ao individuo, familia e comunidade.

Metodologia do processo de enfermagem: $\dot{E}$ a arte de guiar ou orientar a dinâmica das ações sistematizadas de enfermagem, visando a assistência de enfermagem ao individuo, familia e comunidade.

Histórico de enfermagem: E um roteiro sistemático para o levantamento de dados, que sejam significativos para o enfermeiro, do paciente, familia ou comunidade, a fim de tornar possivel a identificação dos seus problemas de modo a, em os analisando adequadamente, chegar ao diagnóstico de enfermagem.

Diagnóstico de Enfermagem: É a identificação das necessidades básicas do individuo (familia ou comunidade) que precisam de atendimento e a determinação, pela enfermagem, do grau de dependência deste atendimento em natureza e extensão.

Plano terapêtico de enfermagem: É a determinação global da assistência de enfermagem que o individuo, familia ou comunidade precisam receber diante do diagnóstico de enfermagem estabelecido.

Plano de cuidados de enfermagem: É o roteiro diário que coordena a ação da equipe de enfermagem na execução dos cuidados adequados às necessidades básicas e especificas de cada paciente e decorrente da implementação do plano terapêutico de enfermagem.

Evolução de enfermagem: É o relato diário das mudanças sucessivas que ocorrem no individuo, familia ou comunidade, enquanto estiver sob assistência de enfermagem.

Prognóstico de enfermagem: $\dot{\mathrm{E}}$ a estimativa da capacidade do paciente, familia ou comunidade em atender suas necessidades básicas afetadas após a implementação do plano terapêutico de enfermagem e a luz dos dados fornecidos pela evolução de enfermagem.

A Teoria das Necessidades Humanas Básicas é publicada mais uma vez, agora em sua forma final, na revista Enfermagem em Novas Dimensões, em $1979^{(8)}$. Nesta última década, a obra de Wanda de Aguiar Horta não sofreu alterações fundamentais. Ela viajou divulgando seu trabalho, criou e manteve a revista Enfermagem em Novas Dimensões e 
trabalhou ativamente no curso de Pós-Graduação da Escola de Enfermagem da USP.

Acreditamos que ainda estamos muito próximos no tempo para dar o real valor a Wanda de Aguiar Horta e seu trabalho.

Sem dúvida sua influência estimulou a muitos de nós e dotou a enfermagem nacional de novas e modernas dimensões.

\section{BIBLIOGRAFIA}

1. HORTA, Wanda de Abuiar Conccito de cnfermagem. Gazeta do povo, Curitiba, PR. 12-5-51.

2. HOR'TA, Wanda de A. Aspectos do conforto do paciente em hospitais. Rev. Brus. Enf., $17(3-4): 114-118,1964$.

3. HORTA Wanda de A. Consideragões sobre o Diagnóstico de Enfermagem. Rcv. Bras. Enf., 20(1):7-13, 1967.

4. HORTA, Wanda de A. Eusino do Plano de Cuidados em Fundamentos de Enfermagem. Rev. Bras. Enf., 20:249-263, 1967.

5. HORTA, Wanda de A. Conceito de Enfermagem. Rev. Esc. de Enf. USP, 2(2):1-5, 1968.

6. HORTA, Wanda de A. Contribuição para uma Teoria de Enfermagem. Rev. Bras. Enf., $22(3,4,5,6): 119-125,1970$.

7. HORTA, Wanda de A. A Metodologia do Processo de Enfermagem. Rev. Bras. Enf., $24: 81-95,1971$.

8. HORTA, Wanda de A. Enfermagem: Teoria das Necessidades Humanas Básicas Enf. Novas Dimems., 5(3):133-136, 1979. 